\title{
What Is The Most Popular Movie Of All Time?: Teaching The Importance Of Ceteris Paribus
}

John Levendis, Loyola University, New Orleans, USA

Craig Santicola, University of New Orleans, and Southeastern Louisiana University, USA

\begin{abstract}
Students often have difficulty understanding the importance of distinguishing between real and nominal prices, or more generally, why ceteris paribus conditions are important. We exploit students' interests in popularity to teach the nominal/real distinction, and the importance of adjusting for inflation, population, and income levels. We illustrate the importance of these topics by asking, "What is the most popular movie of all time?"
\end{abstract}

Keywords: real, nominal, teaching, pedagogy, principles, certeris paribus

\section{INTRODUCTION}<smiles>[C]1C=CCCC=C1</smiles>

tudents in principles of macroeconomics classes often have a difficult time understanding the importance of distinguishing between real and nominal prices, or more generally, why ceteris paribus conditions are important. But students, though, have an intuitive understanding of "popularity". We exploit students' interests in popularity to teach the nominal/real distinction, and the importance of adjusting for inflation, population, and income levels. We offer the following as an introductory discussion to motivate a homework assignment. We presume that students have already been exposed to the concept of the CPI (or GDP deflator); we simply offer an instructive exercise to illustrate why these concepts are important.

In his Principles of Economics textbooks, Gregory Mankiw (2004) uses nominal movie revenues to explain how adjusting for price can influence which movies are the "most popular". We find his treatment lacking and propose the following exercises for students. We have found that this promotes class discussion and increases student interest in what can usually be seen as a dull subject: nominal versus real prices. On several occasions, students who had never participated in class offered constructive criticism. We hope you have similar success with your classes.

Before we present the students with the data, we ask them, "What is the most popular movie of all time?" Students are quick to guess Titanic, although some older students venture E.T.. Among the other most commonly suggested movies are: Star Wars, the Godfather, Gone With the Wind, and the Lord of the Rings trilogy. Invariably, some students start listing silly movies; at least they are engaged. Taking all students' comments seriously, we write each title on the board.

We then vote in class to see which movie students currently like better. In our experience, popularity is split along gender lines, with Titanic usually most popular among our female students, and the male votes split fairly equally between Star Wars, and Lord of the Rings. Such a ranking answers the question, "what is the most popular movie among current economics students present in the classroom?"

So again, we pose the question, "how could we find out what the most popular movie of all time, giving everyone who ever lived, a vote?" And, "what data would you need to answer this question?" Some students suggest 
"dollar returns"; others suggest "tickets sold." Others remain skeptical of both answers, but we find that most students respond with either "dollars" or "tickets".

- $\quad$ How many tickets did they sell?

- How many people saw the movie?

- $\quad$ How much money did they make?

- What percent of the population saw the movie?

- "What might be the virtue of focusing on ticket sales?" They are easily tallied.

- What might be the virtue of focusing on revenues?" They are also easily tallied.

- $\quad$ "How are we different as a country now than in 1955 (for example)?" Here students offer a wide variety of suggestions. Many of them are off the mark. But that is OK, as it eases the stresses of participating in class. The pertinent differences are: inflation, income, standards of living, and population growth.

We explain to the students that just because a movie sold more tickets in 2005 than in 1955 doesn't make it more popular. Perhaps we should take into account that there has been population growth. So we suggest computing for each movie, tickets sold / population

Table 1: The 25 Most Popular Movies in terms of Nominal Revenue

\begin{tabular}{r|l|r}
\hline \hline Ranking & Movie Title and (release year) & Nominal revenue \\
1 & Titanic (1997) & $\$ 600,779,824$ \\
2 & Star Wars (1977) & $460,935,665$ \\
3 & E.T. the Extra-Terrestrial (1982) & $434,949,459$ \\
4 & Star Wars: Episode I - The Phantom Menace (1999) & $431,065,444$ \\
5 & Spider-Man (2002) & $403,706,375$ \\
6 & The Lord of the Rings: The Return of the King (2003) & $377,019,252$ \\
7 & Jurassic Park (1993) & $356,784,000$ \\
8 & The Lord of the Rings: The Two Towers (2002) & $340,478,898$ \\
9 & Finding Nemo (2003) & $339,714,367$ \\
10 & Forrest Gump (1994) & $329,691,196$ \\
11 & The Lion King (1994) & $328,423,001$ \\
12 & Harry Potter and the Sorcerer's Stone (2001) & $317,557,891$ \\
13 & The Lord of the Rings: The Fellowship of the Ring (2001) & $313,837,577$ \\
14 & Star Wars: Episode II - Attack of the Clones (2002) \\
15 & Star Wars: Episode VI - Return of the Jedi (1983) & $310,675,583$ \\
16 & Independence Day (1996) & $309,125,409$ \\
17 & Pirates of the Caribbean: The Curse of the Black Pearl (2003) & $306,124,059$ \\
18 & The Sixth Sense (1999) & $305,388,685$ \\
19 & Star Wars: Episode V - The Empire Strikes Back (1980) & $293,501,675$ \\
20 & Home Alone (1990) & $290,158,751$ \\
21 & The Matrix Reloaded (2003) & $285,761,243$ \\
22 & Shrek (2001) & $281,492,479$ \\
23 & Harry Potter and the Chamber of Secrets (2002) & $267,652,016$ \\
24 & How the Grinch Stole Christmas (2000) & $261,970,615$ \\
25 & Jaws (1975) & $260,031,035$ \\
& $260,000,000$ \\
\hline
\end{tabular}

Other students counter that tickets didn't cost the same then as now, and that somehow we should correct for ticket prices.

It is at this point that we confront the students with the data. We do not know how many tickets were sold for each movie. However, we do know how many dollars each movie made during its tenure at the box office. 
Mankiw's textbook presents the students with nominal movie revenue data which indeed shows that Titanic has earned more dollars as revenue, placing it as the highest grossing movie of all time.

\section{EXPENDITURE, NOMINAL VS REAL}

Mankiw suggests that to properly answer the question, which movie was the most popular we should adjust each movie's revenue so that we are comparing 2005 dollars with 2005 dollars. I.e. we need to adjust for inflation.

Revenue in 2005 dollars $=$ revenue in old dollars x $(2005$ CPI / old CPI $)$

We rank the Top-25 movies in nominal dollars in Table-1, and real dollars in Table-2.

We disagree with Mankiw, however that this simple conversion from nominal to real is the appropriate method. In fact, given the initial student responses, it seems the students also would have disagreed. Recall that many students noticed that populations are very different then than now.

Table 2: The 25 Most Popular Movies by Real Revenue

\begin{tabular}{r|r|r}
\hline \hline Ranking & Movie & Real Revenue in millions \\
\hline 1 & Gone with the Wind (1939) & $\$ 2,160$ \\
2 & Snow White and the Seven Dwarfs (1937) & 1,940 \\
3 & Star Wars (1977) & 1,140 \\
4 & Bambi (1942) & 963 \\
5 & The Sound of Music (1965) & 765 \\
6 & One Hundred and One Dalmatians (1961) & 760 \\
7 & E.T. the Extra-Terrestrial (1982) & 732 \\
8 & Jaws (1975) & 723 \\
9 & The Exorcist (1973) & 679 \\
10 & Titanic (1997) & 665 \\
11 & The Jungle Book (1967) & 627 \\
12 & Star Wars: Episode V - The Empire Strikes Back (1980) & 567 \\
13 & The Sting (1973) & 529 \\
14 & Doctor Zhivago (1965) & 524 \\
15 & Star Wars: Episode VI - Return of the Jedi (1983) & 501 \\
16 & Mary Poppins (1964) & 488 \\
17 & The Godfather (1972) & 472 \\
18 & Star Wars: Episode I - The Phantom Menace (1999) & 465 \\
19 & The Graduate (1967) & 462 \\
20 & Raiders of the Lost Ark (1981) & 433 \\
21 & Jurassic Park (1993) & 426 \\
22 & Grease (1978) & 419 \\
23 & Butch Cassidy and the Sundance Kid (1969) & 413 \\
24 & Spider-Man (2002) & 410 \\
25 & Love Story (1970) & 408 \\
\hline
\end{tabular}

\section{PER CAPITA VS TOTAL EXPENDITURE}

Not only have prices been growing, so has the population of the US. Perhaps it is unfair to rank movies by (real) expenditure. Perhaps we could find out what percent of the population has seen the movie. After all, if popularity means "most people like you" then we need to know what percent of the population likes you. The same goes for movies: what percent of the population saw the movie. 
This seems like a straightforward calculation: data on the population of the US is readily available. But again, we are confounded by the fact that we do not know how many tickets actually got sold. Still, adjusting for population is appropriate and intuitive.

We suggest that students calculate real expenditure per capita. It turns out that this is changes the Top-25 as shown in Table 3. The top movies are largely the same, however Bambi and Start Wars switched between third and fourth places and One Hundred and One Dalmatians and The Sound of Music switch between fifth and sixth places.

\section{INCOME ADJUSTED PER CAPITA EXPENDITURE}

Recall that students also noticed that incomes have changed over the decades. Another measure of popularity might be to rank movies by the percent of the average person's income that he spent on seeing the movie. That is, if the average person spent $5 \%$ of his salary to see Titanic and $25 \%$ to see E.T., then you could argue that E.T. is the more popular movie.

We then suggest the students to calculate per capita real revenue as a percentage of Real GDP.

Table 3: The 25 Most Popular Movies by Per Capita Real Revenue

\begin{tabular}{|c|c|c|}
\hline$\overline{\text { Ranking }}$ & Movie & Per Capita Real Revenue \\
\hline 1 & Gone with the Wind (1939) & $\$ 16.53$ \\
\hline 2 & Snow White and the Seven Dwarfs (1937) & 15.03 \\
\hline 3 & Bambi (1942) & 7.14 \\
\hline 4 & Star Wars (1977) & 5.17 \\
\hline 5 & One Hundred and One Dalmatians (1961) & 4.13 \\
\hline 6 & The Sound of Music (1965) & 3.94 \\
\hline 7 & Jaws (1975) & 3.35 \\
\hline 8 & The Exorcist (1973) & 3.20 \\
\hline 9 & E.T. the Extra-Terrestrial (1982) & 3.16 \\
\hline 10 & The Jungle Book (1967) & 3.16 \\
\hline 11 & Doctor Zhivago (1965) & 2.70 \\
\hline 12 & Mary Poppins (1964) & 2.54 \\
\hline 13 & The Sting (1973) & 2.50 \\
\hline 14 & Star Wars: Episode V - The Empire Strikes Back (1980) & 2.50 \\
\hline 15 & Titanic (1997) & 2.48 \\
\hline 16 & The Graduate (1967) & 2.32 \\
\hline 17 & The Godfather (1972) & 2.25 \\
\hline 18 & Star Wars: Episode VI - Return of the Jedi (1983) & 2.14 \\
\hline 19 & Butch Cassidy and the Sundance Kid (1969) & 2.04 \\
\hline 20 & Love Story (1970) & 1.99 \\
\hline 21 & Raiders of the Lost Ark (1981) & 1.89 \\
\hline 22 & Grease (1978) & 1.88 \\
\hline 23 & Airport (1970) & 1.88 \\
\hline 24 & The Rocky Horror Picture Show (1975) & 1.80 \\
\hline 25 & American Graffiti (1973) & 1.80 \\
\hline
\end{tabular}

Because of the large difference in the scale of the revenue and RGDP variables, we rescale by multiplying by 1000 , thereby dropping the unnecessary and uninformative decimals. We report the Top- 25 in Table 4 . Again we see that holding constant the average income once again changes the movie rankings, but we also encounter diminishing returns to our calculations. That is, we do not gain any substantial new insights by adjusting for real GDP. Five movies did not experience any changes in their rankings at all. The largest mover was Titanic, losing six places in the rankings. Thus, students can see that expenditure on Titanic was not really as Titanic (in terms of a percent of total national income) as were some of their parents' favorite movies. Airport, and Love Story, for 
example, are movies that our students have never heard of. They are, arguably, more important movies, and certainly by our metric, more successful. As a percent of national income, the revenues generated by Titanic do not even rank it in the top twenty movies of all time.

Table 4: The 25 Most Popular Movies by Real Revenue as a percentage of RGDP

\begin{tabular}{r|lr}
\hline \hline Ranking & Movie & Popularity \\
\hline 1 & Gone with the Wind (1939) & 16.46 \\
2 & Snow White and the Seven Dwarfs (1937) & 15.62 \\
3 & Bambi (1942) & 4.71 \\
4 & One Hundred and One Dalmatians (1961) & 1.53 \\
5 & Star Wars (1977) & 1.17 \\
6 & The Sound of Music (1965) & 1.03 \\
7 & Jaws (1975) & 0.86 \\
8 & The Jungle Book (1967) & 0.80 \\
9 & The Exorcist (1973) & 0.80 \\
10 & E.T. the Extra-Terrestrial (1982) & 0.73 \\
11 & Doctor Zhivago (1965) & 0.70 \\
12 & Mary Poppins (1964) & 0.63 \\
13 & The Graduate (1967) & 0.58 \\
14 & The Sting (1973) & 0.54 \\
15 & Star Wars: Episode V - The Empire Strikes Back (1980) & 0.52 \\
16 & The Godfather (1972) & 0.51 \\
17 & Butch Cassidy and the Sundance Kid (1969) & 0.50 \\
18 & Love Story (1970) & 0.47 \\
19 & Star Wars: Episode VI - Return of the Jedi (1983) & 0.46 \\
20 & Airport (1970) & 0.40 \\
21 & Titanic (1997) & 0.39 \\
22 & The Rocky Horror Picture Show (1975) & 0.37 \\
24 & Raiders of the Lost Ark (1981) & American Graffiti (1973) \\
25 & Grease (1978) & 0.37 \\
& & 0.36 \\
\hline
\end{tabular}

\section{CONCLUSIONS}

In the exercises above, once we take into account the major factors such as inflation and the population, we reach diminishing returns. That is, the rankings do not change much after inflation and population are accounted for. However, we have found our students become engaged during this exercise, and continue to offer alternative treatments and ranking schemes, long after the lecture has ended. Maybe this might encourage some students to become economists? Maybe they'll just watch Gone With the Wind.

\section{AUTHOR INFORMATION}

John Levendis is an assistant professor of economics at Loyola University of New Orleans. He received his Ph.D. from the University of Iowa. He has taught economics at the University of Iowa, Cornell College, Southeastern Louisiana University, and Loyola University of New Orleans.

Graig Santicola is a graduate student in financial economics at the University of New Orleans. He has recently taught at the Southeastern Louisiana University.

\section{REFERENCES}

1. Mankiw, Gregory (2004). Principles of Macroeconomics, $3^{\text {rd }}$ ed. Thomson South-Western: Mason, OH. 
NOTES 